06;07

\title{
Эффект электроформовки в поликристаллических пленках фуллерена $\mathbf{C}_{60}$
}

\author{
() И.Б. Захарова, Д.И. Долженко, В.Ф. Бородзюля, Н.Т. Сударь \\ Санкт-Петербургский политехнический университет Петра Великого, Санкт-Петербург, Россия \\ E-mail: irinab.zakharova@gmail.com
}

Поступило в Редакцию 16 ноября 2018 г.

В окончательной редакции 23 ноября 2018 г.

Принято к публикации 23 ноября 2018 г.

\begin{abstract}
Установлено, что в тонкой поликристаллической пленке фуллерена $\mathrm{C}_{60}$ при длительном воздействии на нее постоянного электрического поля напряженностью $1-4 \mathrm{MV} / \mathrm{cm}$ происходит возрастание проводимости на несколько порядков величины - электроформовка. После электроформовки вольт-амперная характеристика демонстрирует высокую степень стабильности тока и воспроизводимость результатов. В полях напряженностью $10^{5}-10^{6} \mathrm{~V} / \mathrm{cm}$ вольт-амперная характеристика формованных пленок определяется током, ограниченным пространственным зарядом. Определены концентрация ловушек $N_{t} \approx 4 \cdot 10^{21} \mathrm{~m}^{-3}$ и их глубина $E_{t} \approx 0.176 \mathrm{eV}$.
\end{abstract}

DOI: 10.21883/PJTF.2019.04.47331.17596

Пленки $\mathrm{C}_{60}$ относятся к классу органических полупроводников с электронным типом проводимости [1]. Они обладают довольно высоким удельным сопротивлением, величина которого при комнатной температуре достигает значений $10^{8} \Omega \cdot \mathrm{cm}$ и существенно зависит как от степени кристалличности пленки, так от и насыщения материала кислородом. Для кристаллического материала проводимость выше, чем для аморфного. При контакте с кислородом электрическая проводимость пленок $\mathrm{C}_{60}$ быстро (в течение нескольких минут) снижается на три-шесть порядков величины [1]. Характер проводимости в пленках $\mathrm{C}_{60}$ прыжковый, причем при комнатных температурах, по-видимому, преобладают прыжки по ближайшим соседям и термоактивированные прыжки на более удаленные молекулы $[1,2]$.

В последнее время тонкие фуллереновые пленки активно используются в различных устройствах органической электроники, при этом могут подвергаться воздействию сильных электрических полей $[3,4]$. Действительно, при рабочих напряжениях $10 \mathrm{~V}$ среднее значение напряженности поля в пленке толщиной $100 \mathrm{~nm}$ достигает $\sim 10^{6} \mathrm{~V} / \mathrm{cm}$. Электрическое поле такой напряженности приводит к инжекции из электродов в пленку носителей заряда и формированию в пленке объемного заряда, что существенным образом сказывается на ее электрофизических свойствах. Вместе с тем эффекты сильного электрического поля в пленках фуллерена исследованы еще недостаточно хорошо, что затрудняет решение многих практических вопросов. Поэтому цель настоящей работы состоит в изучении влияния фактора сильного электрического поля на электрические и диэлектрические свойства тонких пленок фуллерена $\mathrm{C}_{60}$.

Поликристаллические пленки $\mathrm{C}_{60}$ толщиной $250 \mathrm{~nm}$ были получены методом вакуумного испарения молекул фуллерена на холодную подложку из кремния $p$-типа. Пленки $\mathrm{C}_{60}$ имели поликристаллическую структуру с размером кристаллитов $\sim 200 \mathrm{~nm}$ (рис. 1,a). Формируя пленку, кристаллиты хаотично в несколько слоев располагались на поверхности кремниевой подложки (рис. 1,b).

При электрических измерениях кремниевая подложка использовалась в качестве нижнего электрода (катода), а верхний электрод (анод) представлял собой зонд-иглу из индий-галлиевой эвтектики, которая за счет взаимодействия сил поверхностного натяжения и гравитационных сил обеспечивала надежный электрический контакт с тонкой пленкой $\mathrm{C}_{60}$ без ее механического повреждения [5]. Диаметр контактного пятна мог изменяться в диапазоне от 100 до $300 \mu \mathrm{m}$ в зависимости от силы прижима иглы к пленке $\mathrm{C}_{60}$. Все измерения проводились при комнатной температуре в воздухе.

На рис. 2 представлена вольт-амперная характеристика $(\mathrm{BAX})$, полученная на пленке $\mathrm{C}_{60}$ толщиной $L=250 \mathrm{~nm}$ при площади пятна контакта $S \approx 0.03 \mathrm{~mm}^{2}$. Кривая 1 на этом рисунке соответствует ситуации, при которой на образец пленки, ранее не подвергавшейся электрическому нагружению, подается ступенчато возрастающее постоянное (по знаку) напряжение. Время выдержки образца пленки при фиксированном напряжении на каждой ступени составляло несколько десятков секунд. За это время проводилось десять измерений, на основании которых определялось среднее значение измеряемого тока (на рассматриваемых зависимостях оно изображено точками). Отметим, что особенностью BAX при первом электрическом нагружении является ее неустойчивый характер.

После того как напряжение на образце достигло значения $\sim 10 \mathrm{~V}(F=4 \mathrm{MV} / \mathrm{cm})$ его начинали постепенно уменьшать (кривая 2). Регистрируемый при снижении напряжения ток оказывается бо́льшим, чем ток при первом электрическом нагружении. При повторном подъеме напряжения (кривая 3) регистрировались 

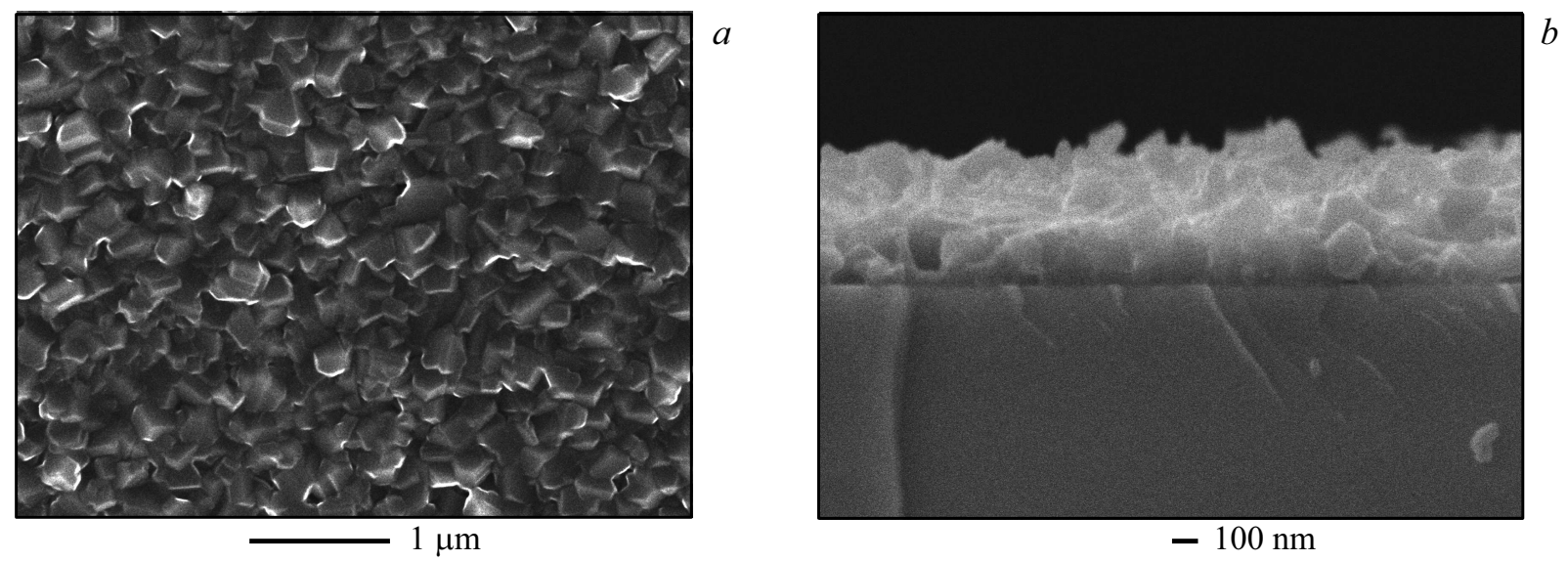

Рис. 1. Изображения поверхности $(a)$ и торцевого скола $(b)$ поликристаллической пленки $\mathrm{C}_{60}$, полученные с помощью растрового электронного микроскопа.

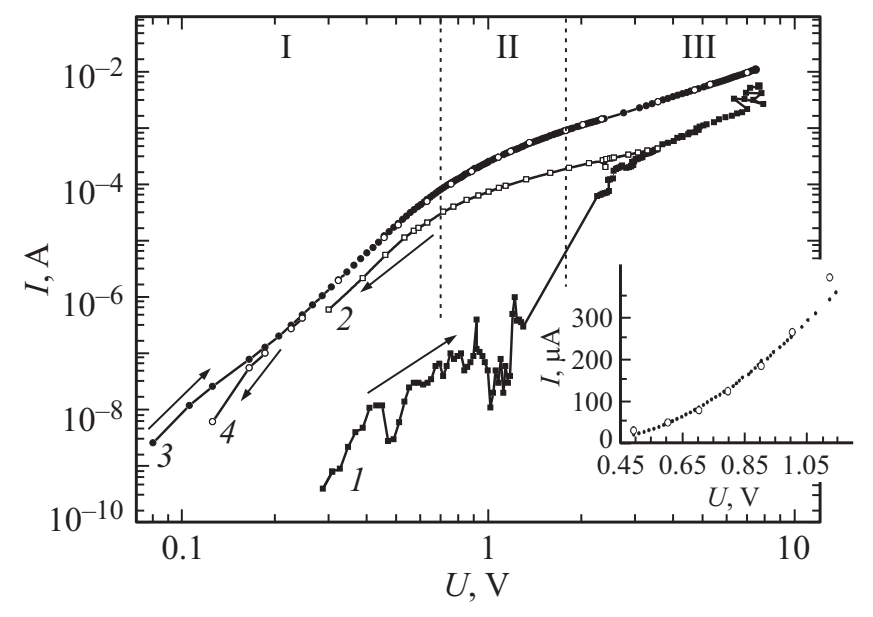

Рис. 2. Вольт-амперная характеристика поликристаллической пленки $\mathrm{C}_{60}$ до $(1,2)$ и после $(3,4)$ электроформовки.

еще бо́льшие занчения тока, но кривая $I(V)$ оказалась гладкой, поскольку всплески тока больше не возникали. Кривая 4 была получена при последующем снижении напряжения на образце. Видно, что кривые 3 и 4 практически совпадают. При дальнейшем повторении циклов подъема и снижения напряжения эксперимент демонстрировал высокую степень стабильности тока и воспроизводимости ВАХ. На микрофотографиях поверхности исследуемой пленки в области пятна контакта электрода с пленкой, полученных с помощью растрового электронного микроскопа после многократного циклирующего воздействия сильного электрического поля, не зафиксировано возникновения особенностей или нарушений ее сплошности.

Возрастание проводимости пленки $\mathrm{C}_{60}$ на несколько порядков величины после длительного воздействия на нее сильного электрического поля можно рассматривать как электроформовку исследуемой структуры. Этот эффект давно известен в сандвич-структурах типа металл-изолятор-металл с аморфными окислами [6,7], но впервые установлен в настоящей работе для тонких поликристаллических пленок $\mathrm{C}_{60}$.

Нелинейный характер регистрируемых после электроформовки ВАХ в исследуемых пленках свидетельствует о том, что в сильных электрических полях реализуется режим тока, ограниченного пространственным зарядом, т. е. $I \sim U^{n}$, где $n$ определяет наклон ВАХ в логарифмических координатах. На кривых 3 и 4 можно выделить три характерные области с различным значением $n$. При $0.1<V \leqslant 0.8 \mathrm{~V}$ зависимость $\lg I$ от $\lg U$ близка к линейной с $n \approx 5$. В области $0.8<U \leqslant 1.9 \mathrm{~V}$ она становится нелинейной, причем значение $n$ уменьшается по мере увеличения приложенного напряжения. Однако при $U>1.9 \mathrm{~V}$ рассматриваемая зависимость вновь линейна c $n \approx 2$. Подобный характер ВАХ указывает на переход от режима предельного заполнения ловушек в области I к ловушечному квадратичному закону в области III [8].

Известно, что напряжение предельного заполнения ловушек $U_{\mathrm{TFL}}$ определяется выражением

$$
U_{\mathrm{TFL}}=\frac{e L^{2} N_{t}}{\varepsilon \varepsilon_{0}},
$$

где $e-$ заряд электрона, $N_{t}$ - полная концентрация ловушек, $\varepsilon$ - диэлектрическая проницаемость пленки $\mathrm{C}_{60}, \varepsilon_{0}=8.85 \cdot 10^{-12} \mathrm{~F} / \mathrm{m}$. Исходя из рис. 2 (по кривой 3) было определено значение $U_{\mathrm{TFL}} \approx 1.9 \mathrm{~V}$. Приняв, согласно [9], для поликристаллических пленок фуллерена $C_{60} \varepsilon=2.6$, из соотношения (1) получим $N_{t} \approx 4 \cdot 10^{21} \mathrm{~m}^{-3}$.

Плотность тока $j$ в области реализации ловушечного квадратичного закона (при $U>U_{\mathrm{TFL}}$ ) определяется соотношением

$$
j=\frac{9}{8} \varepsilon \varepsilon_{0} \mu \frac{U^{2}}{L^{3}},
$$

где $\mu$ - эффективная подвижность электронов при $U>U_{\mathrm{TFL}}$. Поскольку при $U=1 \mathrm{~V}$ ток $I=10^{-3} \mathrm{~A}$ 
(рис. 2, кривая 3), используя соотношение (2), с учетом площади контакта получим $\mu \approx 6 \cdot 10^{-2} \mathrm{~cm}^{2} \cdot \mathrm{V}^{-1} \cdot \mathrm{s}^{-1}$.

Отметим, что данные значения $N_{t}$ примерно на два порядка больше, а $\mu$ меньше, чем значения соответствующих параметров в монокристаллическом $\mathrm{C}_{60}[10]$.

Для оценки глубины ловушек $E_{t}$ было использовано аналитическое приближение ВАХ изолятора с гауссовым распределением ловушек по энергии, имеющее вид

$$
j=\frac{e \mu U}{L} \frac{\left(\varepsilon \varepsilon_{0} U\right)^{\alpha} N_{e} \exp \left(-E_{t} / k T\right)}{\left(e L^{2} N_{t}-\varepsilon \varepsilon_{0} U\right)^{\alpha}},
$$

где $N_{e}-$ плотность состояний на уровне проводимости, $\alpha=\sqrt{\left(2 \pi \sigma^{2} / 16 k^{2} T^{2}\right)+1}, \sigma$ - дисперсия гауссовского распределения. Соотношение (3) может быть применено для аппроксимации экспериментальных данных в ограниченной области изменения напряжения $0.5 U_{\mathrm{TFL}}<U<U_{\mathrm{TFL}}$ и при величинах $n>3[8]$.

С помощью метода наименьших квадратов были определены значения $E_{t}, N_{e}$ и $\sigma$, которые дают наилучшее согласование расчетной (полученной по формуле (3)) и экспериментальной ВАХ. Было получено, что $E_{t}=0.176 \mathrm{eV}, N_{e}=1.9 \cdot 10^{24} \mathrm{~m}^{-3}$ и $\sigma=0.04 \mathrm{eV}$. Участок BAX, построенный при указанных значениях параметров, показан на вставке к рис. 2. Темные точки соответствуют экспериментальным значениям $I(U)$, светлые - расчетным.

Таким образом, представленные результаты показывают, что длительное воздействие на поликристаллическую пленку $\mathrm{C}_{60}$ постоянного электрического поля напряженностью $\sim 10^{6} \mathrm{~V} / \mathrm{cm}$ (электроформовка) приводит к возрастанию ее проводимости на несколько порядков величины и стабилизации электрических свойств. Вольтамперные характеристики формованной пленки в области сильного электрического поля $\left(F>10^{6} \mathrm{~V} / \mathrm{cm}\right)$ соответствуют режиму ловушечного квадратичного закона, при этом концентрация ловушек в щели запрещенных энергий и плотности состояний на уровне проводимости оказываются в 100 раз больше, чем в монокристаллических пленках $\mathrm{C}_{60}$.

\section{Список литературы}

[1] Макарова Т.Л. // ФТП. 2001. Т. 35. В. 3. С. 257-293.

[2] High thermal conductivity materials / Eds S.L. Shindé, J. Goela. N.Y.: Springer, 2006. P. 21-33. doi.org/10.1007/b106785

[3] Yang J.-P., Sun Q.-J., Yonezawa K., Hinderhofer A. // Organ. Electron. 2014. V. 15. P. 2749-2755. doi.org/10.1016/j.orgel.2014.07.010

[4] Тучин А.В., Битюцкая Л.А., Бормонтов Е.Н. // ФТТ. 2014. T. 56. В. 8. C. $1632-1635$.

[5] Бородзюля В.Ф., Мошников В.А., Пермяков Н.В. Измерительный зонд и способ его изготовления. Патент RU 2654385С1. Опубл. 17.05.2018. Бюл. 14. 2 с.

[6] Sevic J.F., Kobayashi N.P. // J. Appl. Phys. 2018. V. 124. P. 164501. doi.org/10.1063/1.5040517
[7] Мордвинцев В.М., Кудрявцев С.E. // Микроэлектроника. 2017. T. 46. № 4. C. 266-274. https://doi.org/10.7868/S0544126917040020

[8] Силиньш Э.А. Электронные состояния органических молекулярных кристаллов. Рига: Зинатне, 1978. 344 с.

[9] Mondal P., Lunkenheimer P., Loidl A. // Z. Phys. B.: Condens. Matter. 1995. V. 99. N 4. P. 527-533. doi.org/10.1007/s002570050072

[10] Головин Ю.И., Лопатин Д.В., Николаев Р.К., Самодуров А.А., Столяров Р.А. // ФТТ. 2006. Т. 48. В. 9. С. 1723-1726. 